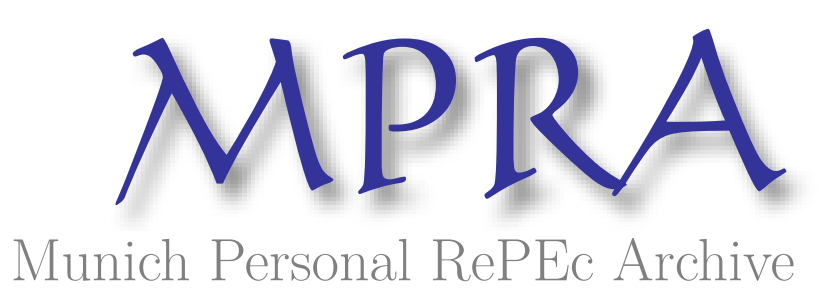

\title{
The Future of Global Reinsurance
}

Chichilnisky, Graciela

1996

Online at https://mpra.ub.uni-muenchen.de/8334/

MPRA Paper No. 8334, posted 19 Apr 2008 04:03 UTC 


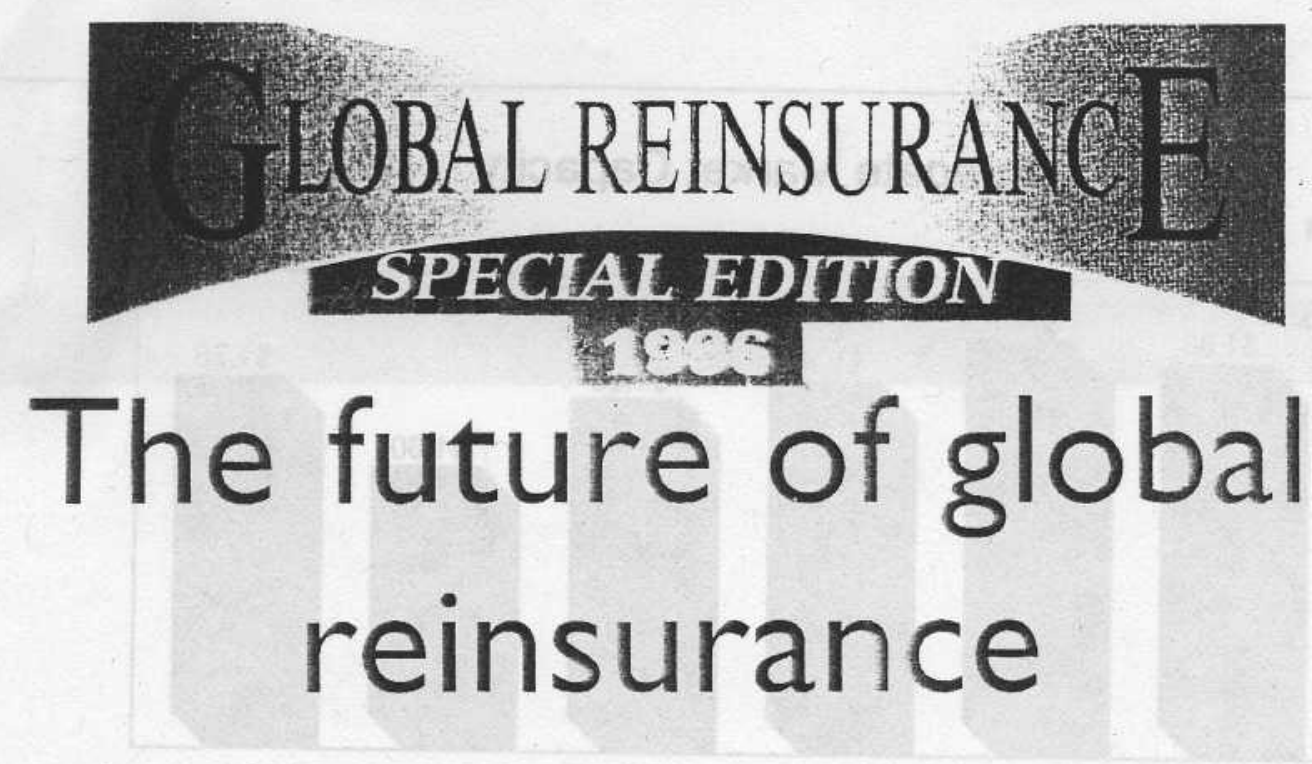

It has been-said that

insurance is the last of the

financial services to accept

radical change.1 Yet there

has been a fundamental shift in the geographical

location and in the

organization of the

reinsurance industry in the

last six years. 2 Global

environmental risks are

partly responsible for this

change. Increased weather

volatility and catastrophic

risks are difficult to

diversify using traditional

insurance practices.

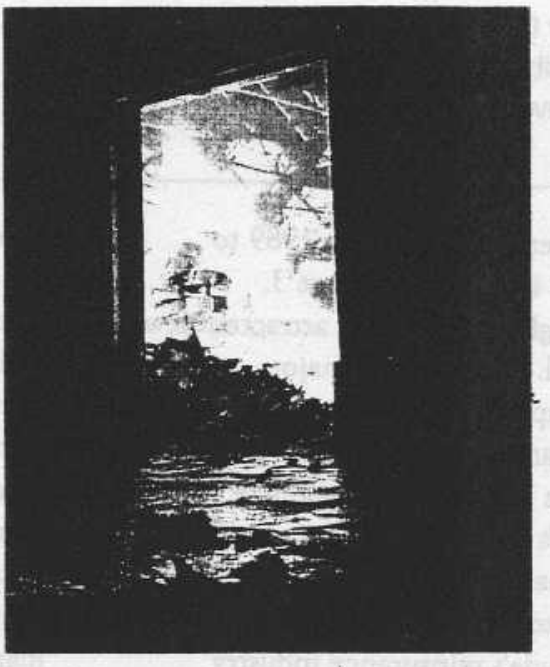

To provide a map to the future, we, need a realistic appraisal of how we got where we are. This is the story of how humans have hedged risks. There are two basic and distinct approaches: statistical and economic. The former is typical of the insurance industry; the latter typifies the securities industry. Both are needed to manage today's catastrophic risks. Neither alone will do. I will show below how a combination of both leads to efficient outcomes, and is the way to the future. ${ }^{3}$

Hedging unknown catastrophic risks requires a blend of skills from the securities and the insurance industries. By tapping large and liquid capital markets, reinsurers will be better able to deal with correlated, catastrophic risks. At the end the intelligent, customized use of derivatives and technology will separate the winners from the losers.
Global environmental risks Weather volatility has made catastrophic risks highly unpredictable. Many scientists believe that climate change could be the source. A recent report by the Intergovernmental Panel on Climate Change (IPCC), charged by governments with investigating global warming, says that humans have a "discernible" influence on global climate. In May 1996 insurance executives confronted the energy industry over global warming, and took their case to the UN Geneva meeting on climate change in June 1996. Their case was heard, and for the first time the US took a leading position in supporting the developing countries' calls for hard targets on the reduction of greenhouse gas emissions in the industrial countries.

Environmental markets which trade the countries' rights to emit have been proposed and loom large on the horizon.

Financial risks

Although the data on climate change is not conclusive, the financial challenge is already real. In the last few years the property/casualty insurance industry has experienced record claims of about $\$ 43$ billion connected with climate volatility. In the United States alone there was the 1988 Midwest drought, the 1993 Midwest floods and 1995 flooding along the Califomia Coast. Hurricane Andrew in 1992 produced.about $\$ 18$ billion of insured losses, and total 
Fig. 1

\section{Aggregate Market Capacity}

$\$$ bilions

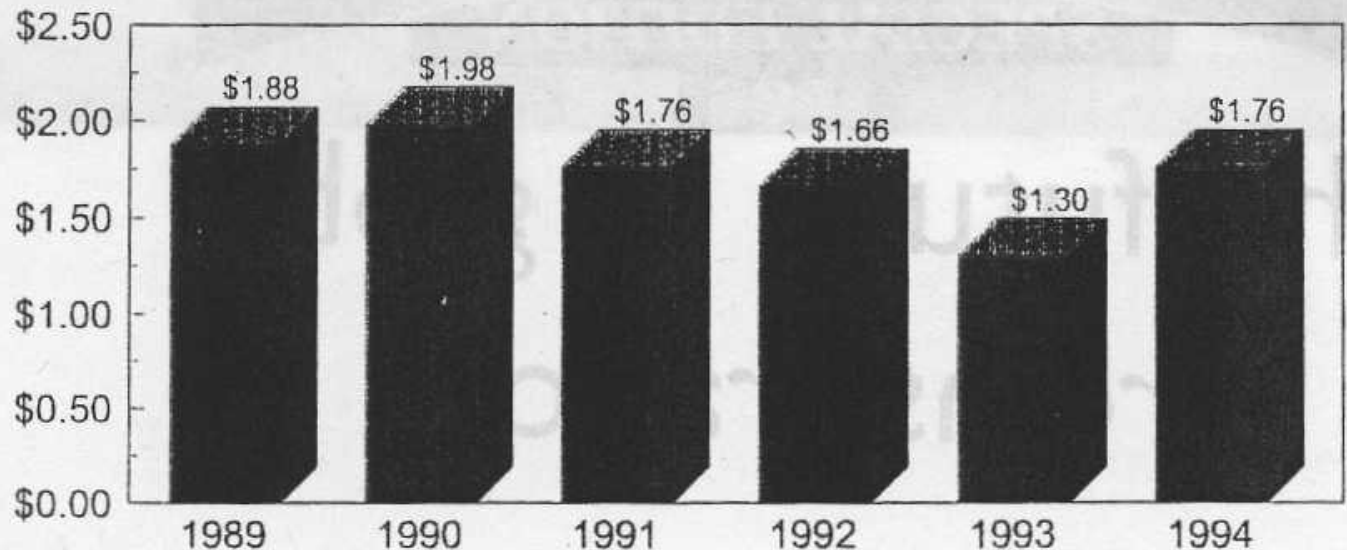

Composite of 14 programs placed by Guy Carpenter \& Co., Inc.

Values indicate placed market capacity; authorized market capacity may have been higher

losses greater than $\$ 25$ billion. ${ }^{6}$

Andrew was the most devastating natural catastrophe ever recorded. It also led to a wave of financial catastrophe: the hurricane affected almost every insurance company in the US. No matter how hard reinsurers tried to diversify their portfolios among different insurance companies, they sustained losses on virtually every account. Not knowing how to hedge unpredictable risks adds the risk of financial catastrophe on top of that of the natural catastrophe, a one-two punch that could lead to a social debacle. The year after Andrew 38 non-US and eight US reinsurers, with names as familiar as Continental $\mathrm{Re}$ and New England $\mathrm{Re}$, either withdrew from the business or ceased underwriting catastrophe reinsurance.?

Reinsurers leave and prices rise Facing an impossible challenge, many. reinsurers left the market. Worldwide reinsurance capacity dropped more than 30\% between 1989 and 1993 , over $20 \%$ of which was due to Andrew, see figure 1 . This naturally led to changes in the marketplace. Insurance companies could not buy enough catastrophe reinsurance, no matter how hard they tried (see figure 2 for placement shortfall percentages). As supply dried up, prices, of course, increased dramatically: the rate on line went from $8.2 \%$ in 1989 to $21.4 \%$ in 1994 , see figure 3 .

Higher prices then attracted new capital. This led to a major geographical shift of the industry 2 illustrated in figure 4 . The continuing doubes of the future existence of Lloyd's of London led to a drop in the UK market share, from about $56 \%$ in 1989 to $23 \%$ in 1995 . Since 1993 Bermuda's reinsurance industry evolved from practically zero to its current position of $25 \%$ of the market. Investment banks are now betting heavily on the reinsurance market. They are the owners of most newly created businesses since 1992 .

Revolution in global finance Together with the geographical shift there has been a substantial shift in the industry's strategy. Insurance derivatives have been recommended for several years and are starting to emerge and play a role. In 1992 we recommended the creation of an instrument to bet on the frequencies of catastrophes, ${ }^{y}$ which the Chicago Board of Trade (CBOT) introduced under the name Catastrophe Futures in 1993. This year Morgan Stanley started marketing a similar instrument: a bond issue whose returns are linked to hurricane frequency and severity in the current US season. ${ }^{9}$ Last. week Merrill Lynch structured a transaction for USAA, the country's largest direct marketer of home and car insurance, offering $\$ 500$ million in bonds on the US capital markets which are tied to the company's losses from hurricanes. ${ }^{10}$ Financial innovation in reinsurance markets is slowly taking shape, but the pace is relentless. Everyone knows that access to more liquid capital markets is essential to the reinsurance industry. The derivatives market is the key to liquid and flexible trading of weather risks.

With the influx of newcomers the reinsurance industry is facing today heightened competition and consolidation after five years of heady revenue growth and strong earnings. Technology has become more important than ever, as the new derivative instruments require swift and controlled action. Technology is needed to face the challenge of unknown risks.

\section{Unknown risks}

What are unknown risks? These are risks whose frequencies we do not know, and for which we are aware of our ignorance. ${ }^{11}$ You could think of these as risks for which we have more than one actuarial table, each equally likely. There is more than one prior estimate of the frequency of the event. ${ }^{12}$ 
Example of unknown risks are environmental health risks of new and little known epidemics; risks induced by scientific uncertainty in predicting the frequency and severity of catastrophic events, such as nuclear reactor and satellite risks. These risks are driving major changes in the insurance and reinsurance industry today. ${ }^{13}$

Take a simple example. One reliable source gives a $2 \%$ annual chance of the occurrence of a hurricane of a certain type, and another a $12 \%$ chance. Montecarlo simulations and other procedures can be used to attempt to tease from all models a unique statistical approximation to the true frcquency. But what if there is no true frequency?

How could this be? Easily. There may be two possible climate patterns, both equally likely.

Indeed, many climate experts view climate as a fundamentally non-linear phenomenon in which chaotic patterns emerge easily. Such systems can have two "attractors," or two distinct overall patterns of behavior, each equally likely. Each of these attractors describes a weather pattern, a reasonable statistical inference of the frequencies of major events. In such a chaotic system, it is scientifically impossible to predict from the initial conditions which of the two patterns the climate will result: a pattern with two hurricanes a year, or the other with a dozen.

The first statistical reaction is to construct a new actuarial table by taking an average, in this case 7. But taking an average does not help. It only ensures that one is wrong $100 \%$ of the time: $50 \%$ of the time one is overinsured (the pattern with two hurricanes per year) and the other $50 \%$ underinsured (the pattern with a dozen a year). Both have major financial costs. In our case, if each hurricane leads to $\$ 2$ billion in losses, then the averaging method leads to a $\$ 10$ billion shortfall $50 \%$ of the time and $\$ 10$ billion overinsurance the other $50 \%$ of the time. Hardly a considered way to manage risks.

Is there a solution to this problem? The good news is that there is. It is possible to hedge such unknown risks successfully and efficiently. To do so, however, one needs a careful and customized approach which blends in both insurance and securities * approaches to hedging risks.

Two ways to hedge risk Insurance: the statistical approach The statistical approach to hedging risks relies on the law of large numbers and is the traditional foundation of the insurance industry.

For this to work, risks must be reasonably independent across individuals or groups, and the frequencies must be known. Loss of life and car accidents are typical examples. Here the law of large numbers operates.

There is safety in numbers: with a large enough population the number of those likely to be affected is known with considerable accuracy. The sample mean is highly predictable if the distribution for each person or group is known. This is the standard principle on which insurance operates. Reinsurance is simply a way to augment the pool of those affected so that the law of large numbers operates better. All this is needed is a reliable actuarial table describing the incidence per person or group, and a large pool of insureds to distribute the risk. $^{14}$

If the numbers are not large enough, it is standard to spread risk through time. The number of people affected by a hurricane over a 10 years period is at least 10 times that affected in one year. This requires that the risks be independent through time, eliminating irreversible risks such as a once-and-for-all shifts arising from global warming

Hurricanes such as Andrew (1992) and Opal (1995), however, defy the law of large numbers. They affect large areas all at once, both in

Fig. 2

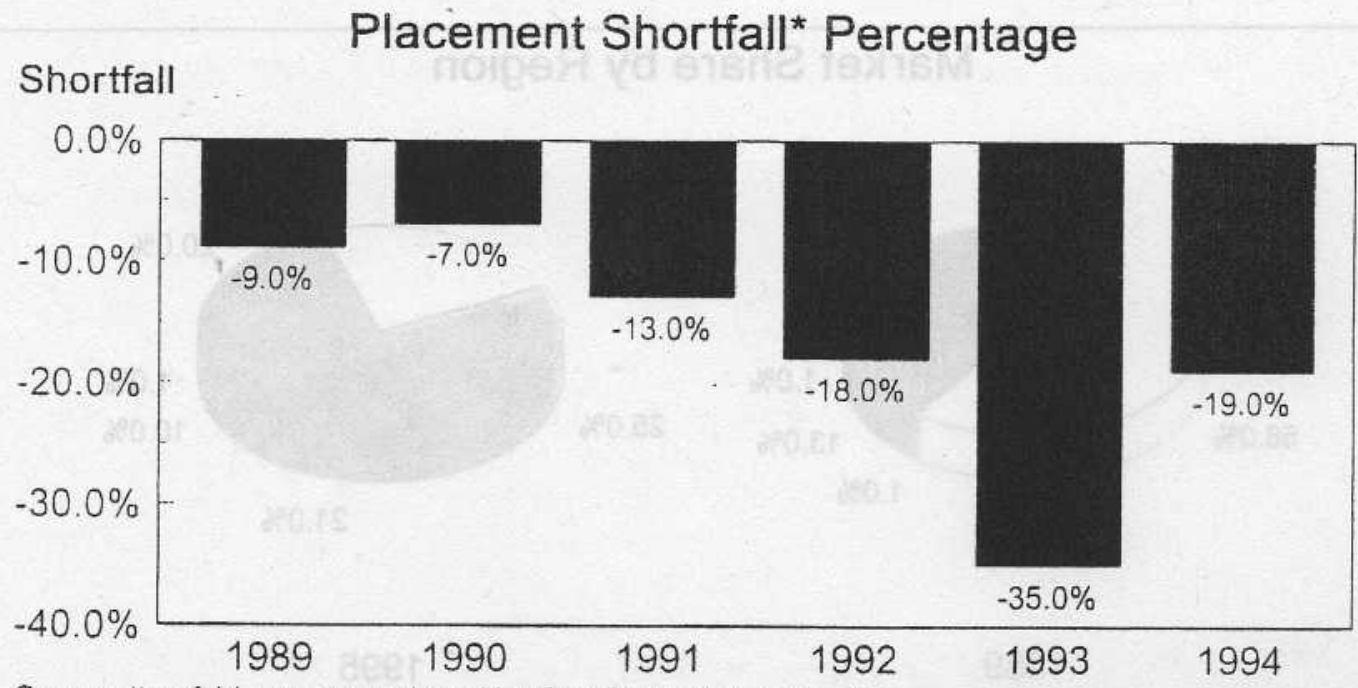

Composite of 14 programs placed by Guy Carpenter \& Co., Inc.

- Shortfall is the difference between the amount of coverage desired and the amount of coverage available in the market 


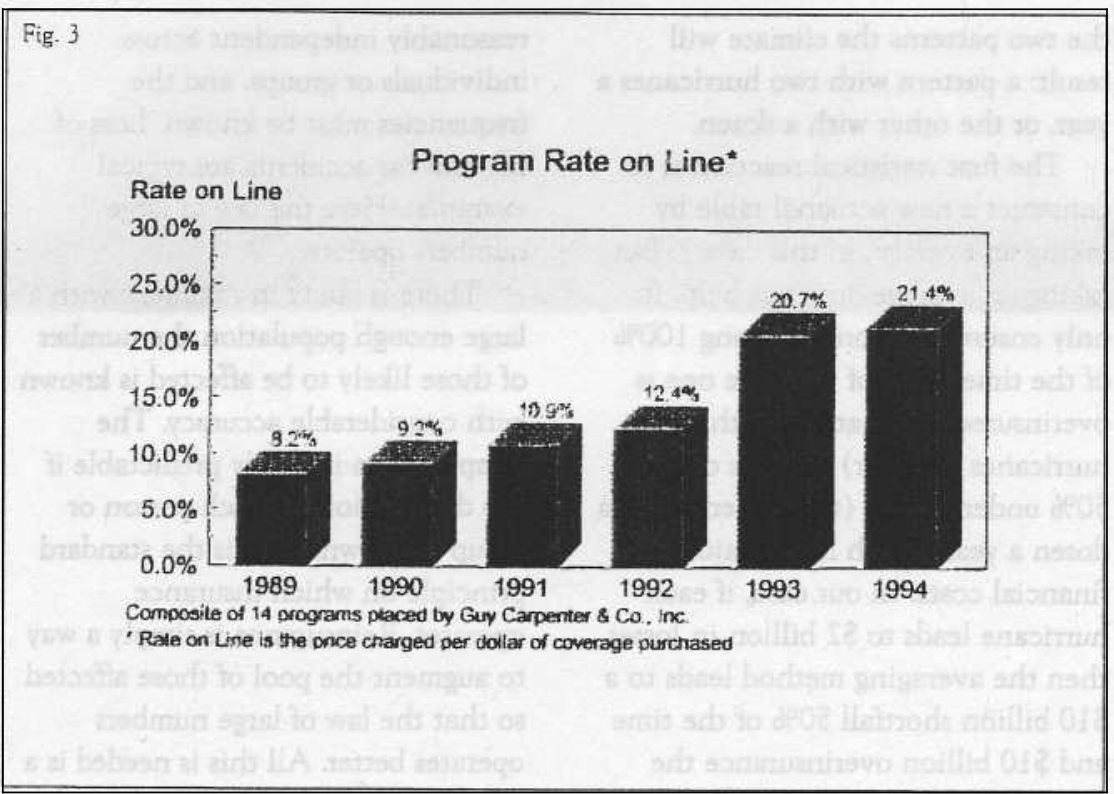

physical and in financial terms, and their frequency and severity seems to be changing. The actuarial table itself has become the risk. Insurance does not work. What are the alternatives?

Derivatives: the economic approach The alternative is the economic approach. This works best for correlated risks, in which the same event occurs for many people all at once. A drop in the value of the dollar is an example: the event is the same for everyone in the US economy. There is no way to pool this risk: however, as we all know, we can hedge it by using derivatives (currency futures or options). The principle used here is negative correlation. One hedges by taking a position which is highly correlated with the risk, only with the opposite sign.

For example, an investor with a dollar based portfolio who fears a drop in the value of the dollar can buyza future contract in yen, or a dollar put. If the dollar drops in value he is covered by the increase in the value of the derivative. Bear funds have been constructed on this principle.

The economic procedure is radically different from the insurance approach in that it does not require a large number of people. Nor does it require knowing the frequency of the event or the actuarial table. This fundamentally different method is the way the securities industry operates. Instead of pooling risks, one trades risks.

Securities markets are, however, notoriously complex. For example the procedure of trading risks just outlined makes no sense for individual risks, such as death. How to describe the death of one single person within a large economy as one event on which all of us can trade? To do so would require an unrealistically high number of securities, indeed $2^{*}$, where $x$ is the number of people in the economy. In a world with five billion people the number of securities could exceed the number of all known particles in the universe.

Insurance, instead, deals with such risks expeditiously: if all individuals are in the same risks class, one insurance contract would suffice. The contrast is stark, but it makes a point. In a world of unknown risks neither securities nor insurance methods work in isolation.

The ideal hedge: catastrophe bundles We saw that insurance does not work when the frequency of a risk is unknown, and securities do not work when the risks are individual. Neither of these two approaches works on their own, then, what does work?

The ideal hedge is a combination

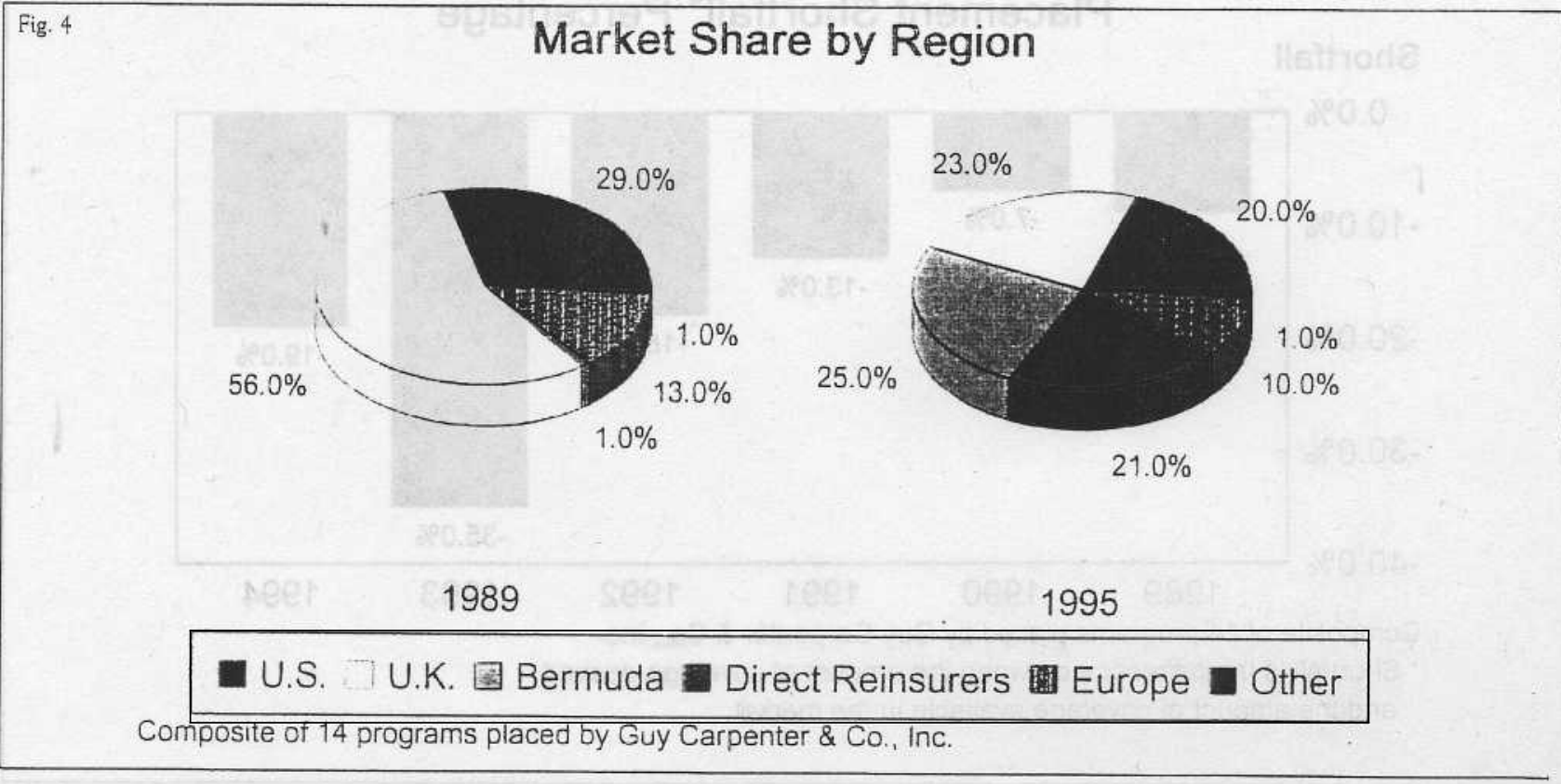


of insurance and securities: this can achieve efficient allocation of risk bearing. I call this a catastrophe bundle because it bundles up two types of instruments. It consists of a modified insurance instrument, which provides insurance contingent on the frequency as observed after the fact, and of a novel derivative security for betting on the frequency itself. ${ }^{15}$

The latter type of security has emerged and is now traded in the CBOT; as mentioned above related securities have recently emerged also in the form of bonds floated by Morgan Stanley and Merrill Lynch.

The insurance instrument required is a modified version of mutual insurance. It differs fundamentally from the standard mutual insurance in that a large pool of insureds is unnecessary.

The combination of both instruments ensures that no financial catastrophe will occur, since the reinsurer is not exposed to more risks than it can afford. Yet this approach can be used to provide nearly full coverage for the insured.

Elsewhere I have shown that such instruments lead to an efficient allocation of risk bearing. ${ }^{16}$ They require a carefully customized approach to hedging risk. This gives the traditional face-to-face insurance approach an edge over raw technology.

How do catastrophe bundles work? The instrument works best in the hands of an experienced reinsurer or broker who can customize it to his or her client's needs. In a way, the reinsurer is selling a package which consists of insurance, a security and a risk management/consultancy tool.

Together with the client one must first identify the set of possible descriptions of the risk. This part of the process is crucial and it involves new techniques of risks management. This is best handled in a face-to-face and customized basis. A mathematical formula is then brought to bear in the customization of catastrophe bundles to the customer needs. This formula works very well when there is more than one pattern of risk and therefore more than one "possible" actuarial table, each table being substantially likely. After this is achieved, introduce derivative securities whose payoffs depend on which description of the risk is correct, which are effectively transfers contingent on distributions. Finally one structures insurance contracts which establish a compensation arrangement in a way that depends on which description of the risk is correct. These contracts have a lot in common with old fashioned off-track betting on 'bookie' shops.

\section{Pricing and optimal portfolios}

Fund managers can look at the flip side of this picture and seek a combination of insurance and securities which offers an optimal portfolio in insurance and investment markets. A part of this instrument is what Merrill Lynch and Morgan Stanley floated recently. Securitizing such instruments is, of course, the next step.

Through the use of catastrophe bundles, the reinsurance broker can access a large pool of managed funds while offering its clients a customized reinsurance service which manages risks optimally, and at very competitive prices.

Pricing is, of course, a crucial issue. What is needed here is to separate two parts of the risk and push each as far as they will go. The contingent insurance part of the instrument should be applied as far as possible, covering the independent part of the risk for which it is optimally suited. Securities are then used for what they are best: the correlated part of the risk. A mathematical formula used to construct the catastrophe bundle separates and prices both parts.

\section{Convergence of insurance and securities markets}

It is no secret that the securities industry is making inroads into the reinsurance business. By itself, however, it cannot succeed, because the individual parts of the risks cannot be handled efficiently by securities markets: they are too cumbersome for individual risks. Insurance, based on the law of large numbers, has an important place in simplifying financial transactions and hedging known individual risks.

Catastrophe bundles offer one approach to computing the limits of each instrument, and blending them optimally to achieve the most competitive pricing of a catastrophe reinsurance portfolio.

The fucure of the industry is in the hands of those who achieve the perfect balance, through integrating derivative securities with contingent insurance contracts, and integrating technology with customized face-toface know-how. The future, I may add, is here today.

Graciela Chichilnisky is UNESCO

Professor of Economics and Mathematics at Columbia University. She has taught at Harvard, Essex and Stanford Universities and was from 1986-89 chairman and ceo of FITEL, an international financial

3. telecommunications corporation.

She has been advisor to the Organization of Economic Co-operation and Development, the United Nations and the Organization of Petroleum Exporting Councries, in international economics and environmental policy.

1. Valerie Denney: 'Ediror's Nore', Global Reinsurance. December 1995-February 1996, p.14

2. G. Chichilinisky: 'Financial Innovation in Property

Catastrophe Reinsurance: the Convergence of Insurance and Capital Markets," Risk Finmang Newsietrer, Vul. 13, No 2., June 1996, p.1-7.

3. O. Chichilnisky: 'Catastrophe Bundles Can Deal with

Unicnown Risks', Best's Review, February 1996, p.1-3.

4. L. Boutron: 'Debate Warms Up' Financial Times, Business and the Environment, p. 10, May 29, 1996.

5. G. Chichilnisky: 'The Greening of Bretton Woods' Financial Times, January 2, 1996, advanced a proposal for a global market on greenhouse gas emissions and an International Bank for

Environmental Secclements $\mathrm{m}$ handle executions, clearing and setrlements as well as regulating botrowing and lending rates.

6. G. Chichilnisky, Best's Review, op. cit.

7. G. Chichilnisky: Risk Financing, op. cit.

8. G. Chichilnisky and G. M. Heai: 'Global Environmental

Risks' Joumal of Economuc Perspectives. Fall 1993, p.65-86.

9. Barron's July 8, 1996 ,

10. R. Wacers: 'Investors get chance to gamble on weacher: US insurance group linics bonds to hurricane losses' Financial Tmes. July $30,1996$.

11. G. Chichilnisky: 'Markers with Endogenous Uncertainty: Theory and Policy' fortheoming in Theory and Decision, 1996 12. D. Cass, G. Chichilnisky and H, Wu 'Individuai Risks and Mutual Insurance' Econometrica, Vol. 64, No. 2, March 1996 , p.333-341.

13. O. Chichilnisky and G. M. Heal 'Catastrophe Bundles: Financial Markets and Changing Climate Risks' fortheoming in Economic Aralysis, Springer Veriag.

14. G. Chichilnisky and G. Heal 'Carascrophe Bundles', op. cit 15. G. Chichilnisky: Best's Review, op. cit.

16. See Chichilnisky and Heal "Global Environmental Risks", "Catastrophe Bundles: Financial Markets and Global Climate Risles" op. cit., and Cass, Chichilnisky, Wu "lndividual Risks and Mutual Insurance" op, cit. 